Acta Sci. Pol. Technol. Aliment. 18(3) 2019, 279-292

pISSN 1644-0730

eISSN 1898-9594

http://dx.doi.org/10.17306/J.AFS.2019.0658

ORIGINAL PAPER

Received: 11.04 .2019

Accepted: 5.07.2019

\title{
NANOTECHNOLOGY FOR ENHANCING THE PRODUCTION OF MEAT-LIKE FLAVOUR FROM ENZYMATIC HYDROLYZED SOYBEAN PROTEIN ISOLATE
}

\author{
Hoda H. M. Fadel ${ }^{1 凶}$, Khaled F. Mahmoud ${ }^{2}$, Rasha Saad ${ }^{1}$, Shereen N. Lotfy ${ }^{1}$, \\ Fatma Sh Abd El-Aleem ${ }^{1}$, Mohamad Y. S. Ahmed ${ }^{1}$ \\ ${ }^{1}$ Chemistry of Flavour and Aroma Department, National Research Centre \\ Al-Buhouth St. Dokki, 12622 Cairo, Egypt \\ ${ }^{2}$ Department of Food Science and Technology, National Research Centre \\ Cairo, Egypt
}

\begin{abstract}
Background. Enzymatic hydrolyzed vegetable proteins have been recommended as safe precursors of process flavours. However, the degree of hydrolysis limits their production on an industrial scale. Nanotechnology can enhance the enzymatic hydrolysis of soybean protein. Therefore, the aim of the present study was to use the enzymatic hydrolyzed soybean protein isolate (E-SPI) nanoparticles for producing a high yield of meat-like process flavour.

Material and methods. Ball milling, high-speed homogenization and ultra-sonication were used for preparation of SPI nanoparticles with average range 10-17 nm. The volatile compounds were analyzed by headspace solid phase microextraction (HS-SPME) and gas chromatography coupled with mass spectrometry (GC-MS). The odour attributes of beefy, roasty, savoury, sulphurous and overall acceptability were selected to describe the meat-like process aroma.

Results. The total volatiles in the headspace of the meat-like process flavour based on SPI nanoparticles showed a higher yield compared with the untreated sample. Thiols containing compounds, especially the potent odorants of meat-like flavour, were predominant in both samples. However, their yield was significantly higher in the SPI nanoparticles sample. An agreement was found between the intensity of the attributes selected and the aroma composition of the two meat-like flavours investigated.

Conclusion. The results of this study suggest that using protein nanoparticles as the main precursors of the process flavours is considered a new chance for innovation in nanoscience. Future studies will be carried out on improving the quality and quantity of vegetable protein nanoparticles that can be used as precursors of another process flavours.
\end{abstract}

Keywords: protein nanoparticles, odour sensory analysis, meat-like process flavour, transmission electronic microscope, soybean protein isolate

\section{INTRODUCTION}

Thermal process flavourings are mainly used to obtain the characteristic flavour of thermal-treated foodstuffs, especially meats (Song et al., 2010; Song and Xia,
2008; Wu and Cadwallader, 2002). The international organization of the flavour industry recommended the enzymatic hydrolyzed vegetable proteins (E-HVP)

凶odafadel_f@hotmail.com, https://orcid.org/0000-0003-0363-1409, phone +201 003925237, fax 20233370931 
as safe flavour precursors for process flavourings (IOFI, 2010).

Extensive studies have been conducted on the thermal generation of volatile compounds using E-HVP (Baek et al., 2001; Wu and Cadwallader, 2002). In our previous studies, the effect of different thermal treatments on the production of a beef-like flavour from E-HVP was evaluated (Lotfy et al., 2015). However, enzymatic hydrolysis has many disadvantages, such as a low degree of hydrolysis, a low yield of polypeptides and wasting time (Liu et al., 2008). Consequently, the industrial production of process flavourings is facing enormous challenges for developing and implementing systems that can produce high production, high quality and safe E-HVP. To solve this problem, innovation is needed to produce novel techniques for producing a high yield of E-HVP.

Nanotechnology can possibly improve the industrial production processes of food to provide products with better characteristics and new functionalities (Neethirajan and Jayas, 2011). According to the National Nanotechnology Initiative (Arlington, VA, USA), nanoparticle sizes vary in range from 1 to $100 \mathrm{~nm}$. As the size of the particles gets reduced to the nanoscale range, their reactivity increases and mechanical, electrical and optical properties changes (Neethirajan and Jayas, 2011). Protein-based nanoparticles are very interesting as they are relatively easy to prepare and their sizes distribution can be monitored (DeFrates et al., 2018). Soybean protein isolate (SPI), the enriched form of soy protein, is one of the plant proteins most widely utilized as a food ingredient (Liu et al., 2008; Riche and Williams, 2010; Yu et al., 2008). It possesses a balanced composition of polar, non polar and charged amino acids.

Nanotechnology improved the characteristics of the enzymatic hydrolyzate of soya protein (Rogov et al., 2011). The particle sizes of the nanoparticles produced ranged from 40 to $50 \mathrm{~nm}$, whereas the particle sizes of the natural protein were ranged from 100 to $400 \mathrm{~nm}$. The protein nanoparticles exhibited hydrophilic groups on their surface and a rupture of crosssection communications.

Protein nanoparticles can be produced by several methods. Nanomilling technology is an efficient and relatively cheap method for the production of nanosize materials (DeFrates et al., 2018; Williams et al., 2013).
Recently, significant advancements and evolutions in milling processes have been enabled the production of nanoparticles (Loh et al., 2015). Ball milling is a simple process and environmentally acceptable. Selecting the appropriate operating conditions gives rise to the production of the desired nanoparticle sizes (Roa et al., 2014). High-pressure homogenization is increasingly used to produce nanoparticles, it is very effective in generating and stabilizing the newly prepared nanomaterials (Merisko-Liversidge et al., 2003; Van Eerdeubrugh et al., 2008). A high-pressure homogenization procedure has been developed for the formation of stable and functionalized protein nanoemulsion (Loureiro et al., 2015). Ultrasonic is a promising technology for the formation of nano and micro materials (Lilliehorn et al., 2005). It has been used by the pharmaceutical industry for improving and controlling the particle size. Ultrasonication is a post reaction processing for the production of nanoparticles in the liquid phase (Schroeder, 2013).

Extensive studies have been published concerning the using of protein nanoparticles for food and drug delivery systems (Rahimnejad et al., 2009; Verma et al., 2018). Soybean isolate nanoparticles showed promising properties as a delivery system for drugs or nutraceuticles. However, to the best of our knowledge, no study has yet been found concerning the preparation of meat-like process flavour based on enzymatic hydrolyzates of protein nanoparticles.

Therefore, the main objective of the present study was to use nanotechnology to improve the yield of meat-like process flavour prepared from enzymatic hydrolyzed soybean protein isolate (E-SPI) nanoparticles. To achieve this aim, different nanotechnology tools were used to assist the enzymatic hydrolysis of SPI. Soybean protein isolate nanoparticles were prepared before the enzymatic hydrolysis in three steps (ball milling, homogenization and ultra-sonication). Each tool was applied at different time intervals and the sample showing the smallest nanoparticle sizes was selected and subjected to further analysis. The degree of enzymatic hydrolysis and composition of the free amino acids released were evaluated. The sample of enzymatic hydrolyzed SPI nanoparticles which showed the best results was selected and used as a main precursor, with other flavour precursors, of a meatlike flavour. The flavour produced was evaluated 
with regard to headspace volatiles and odour profile in comparison with that produced from the untreated enzymatic hydrolyzed SPI (control).

\section{MATERIAL AND METHOD}

\section{Plant materials and chemicals}

Soybean protein isolate SPI ( $80 \%$ protein) was obtained from Miro for Export \& Import Co. Cairo, Egypt. Leucine, ninhydrin, $\mathrm{CdCl}_{2}$, ethanol $99.5 \%$ and acetic acid were purchased from Sigma Aldrich Chemical Co. (St. Louis, MO, USA). Flavourzyme (from Aspergillus oryzae) and Alcalase (from Bacillus licheniformis) were obtained from Novo Nordisk A/S (Bagsvaerd, Denmark). All the chemicals used in this study were of analytical grade and solvents were purified and distilled before use.

\section{Preparation of SPI nanoparticles}

Nanoparticles preparation was carried out in three steps; ball milling, homogenization and ultrasonication. A planetary ball mill model (PQ-N2 Gear Drive 4-station, USA) was used at a rotation speed of sun wheel $290 \mathrm{rpm}$, planetary jars $580 \mathrm{rpm}$ and frequency converter $40 \mathrm{~Hz}$. Stainless steel balls (250) were used with a size range of between $0.5-1 \mathrm{~mm}$, the process was conducted in two time periods $-1 \mathrm{~h}(\mathrm{~A})$ and $1.5 \mathrm{~h}$ (B) at 220v. The two milled samples $\left(\mathrm{SPIN}_{1} \mathrm{~A}\right.$ and $\mathrm{SPIN}_{1} \mathrm{~B}$ ) were subjected to transmission electron microscope (TEM) analysis (as will be mentioned below). The sample showed the smallest particles sizes was selected and subjected to high-speed homogenization (HSH) and ultrasonication (US).

The selected ball milled SPI sample $(75 \mathrm{~g})$ was added to $900 \mathrm{ml}$ of distilled water and subjected to the homogenization technique (Homogenizer PR0400PC-China) at $1800 \mathrm{rpm}$ by varying the time from 10,15 and $20 \mathrm{~min}$. During the homogenization process, the samples were placed in a water bath with cold water at $4^{\circ} \mathrm{C}$ to prevent the suspension overheating. The particle sizes of each homogenized sample was measured by TEM and the sample showed the smallest particle sizes was ultrasonicated using an ultasonic probe (Probe Sonicator Sonics, VCX-750 Vibra-Cell Sonicator, USA) with a diameter of $3.8 \mathrm{~mm}$, and applied at $160 \mathrm{~W}$ with $50 \%$ pulse at 15 and $20 \mathrm{~min}$. In order to prevent re-crystallization during the process, the production temperature was kept at least $5^{\circ} \mathrm{C}$ above the protein melting point. The ultrasonicated sample showed the smallest particle size was selected and subjected to further analysis.

\section{Transmission Electron Microscope (TEM) of SPI nanoparticles}

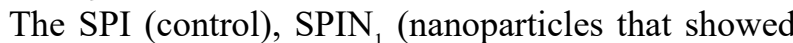
the smallest sizes after one nanotechnology step, ball milling) and $\mathrm{SPIN}_{3}$ (nanoparticles formed by three nanotechnology steps; ball milling, HSH and US) samples were diluted to $1 \%$ with distilled water and sonicated for $3 \mathrm{~min}$ in an ultrasonic bath. Twenty microliters of each diluted sample was placed on a film-coated 200-mesh copper specimen grid for $10 \mathrm{~min}$ and the excess fluid was eliminated using filter paper. The grid was then stained with one drop of $3 \%$ phosphotungstic acid and allowed to dry for $3 \mathrm{~min}$. The coated grid was dried and examined under a TEM microscope (JED 1230, JEOL Ltd., Tokyo, Japan). The samples were observed by operating at $160 \mathrm{kV}$ (Saloko et al., 2013).

\section{Production of enzymatic SPI nanoparticles hydrolysate}

Enzymatic hydrolysis of the control sample and the selected SPI nanoparticles sample was carried out, according to Aaslyng et al.'s procedure (1998). Flavourzyme and Alcalase were used for hydrolysis of the protein. The hydrolysate of each sample was subjected to centrifugation and the precipitate was washed with $300 \mathrm{~mL}$ of distilled water and centrifuged again. The combined hydrolysates in water were filtered, freeze-dried (Snijders Scientific b.v. Model L45 Fm-Ro, Tilburg, Holland), and stored immediately in closed glass bottles at $10^{\circ} \mathrm{C}$ pending further analysis. The content and composition of the free amino acids of each enzymatic hydrolyzed protein (E-HVP) was determined according to Lotfy et al.'s procedure (2015).

\section{Degree of hydrolysis (DH)}

The degree of hydrolysis was determined by using a spectrophotometric method based on the reaction between Cd-ninhydrine reagent and free amino groups (Folkertsma and Fox, 1992). The absorbance was determined at $570 \mathrm{~nm}$. A standard solution containing $100 \mathrm{mmol} / \mathrm{L}$ leucine was prepared for quantitation. The analysis was performed in triplicate. 


\section{Preparation of meat-like flavour}

A mixture of freeze-dried E-HVP (5 g) of each sample with $1.0 \mathrm{~g}$ xylose and $1.0 \mathrm{~g}$ of a mixture containing cysteine, methionine and thiamine (at equal molar ratio) was dissolved in a phosphate buffer $(25 \mathrm{~mL} ; 0.5$ $\mathrm{M} ; \mathrm{pH}$ 5) and transferred to a $50 \mathrm{~mL}$ screw-sealed tube, tightly capped and then heated in a thermostatic oil bath with magnetic stirring $(150 \mathrm{rpm})$ at $140^{\circ} \mathrm{C}$ for $60 \mathrm{~min}$. After the reaction, the tube was immediately cooled in ice-water to room temperature.

\section{Odour profile analysis}

Evaluation of odour profile of each sample was carried out according to Lotfy et al.'s procedure (2015) for evaluating the odour profile of meat-like process flavour. The evaluation was conducted by a well-trained panel consisting of 20 members (12 female, 8 male) drawn from the Food Technology and Nutrition Division, National Research Centre, Cairo, Egypt. The panelists had thoroughly discussed aroma properties of the samples through three preliminary sessions, each session lasting $2 \mathrm{~h}$, until all of them had agreed to use the selected attributes according to the objective of the present work. Five aroma descriptors, including beefy, roasty, savoury, sulphurous and overall acceptability, were selected for the quantitative descriptive sensory analysis. The individual panelists separately scored the intensity of descriptive odour qualities on a category scale 0.0 (not perceptible) to 10.0 (strongly perceptible). The analysis was carried out in triplicate.

\section{Isolation of volatiles}

A divinylbenzene/carboxen/polydimethyl siloxane (DVB/CAR/PDMS) fiber (coating thickness: 50/30 $\mathrm{mm}$ ) was used in solid phase microextraction analysis (SPME; Supleco, 57348-U, Bellefonte, PA, USA). This fiber showed a high ability to extract the expected volatile compounds (Moon et al., 2006). The optimum extraction conditions (time and temperature) of the target volatile compounds were investigated according to Fadel et al.'s procedure (2018). An extraction time of $70 \mathrm{~min}$ at $60^{\circ} \mathrm{C}$ produced the optimum results for all compounds investigated, and was therefore chosen for SPME of the volatiles in the headspace of each sample. Each sample $(50 \mathrm{~mL})$ was placed in a 100 $\mathrm{mL}$ headspace vial sealed with a PTFE-faced silicon septum (Supelco, Bellefonte, PA, USA). Extraction was performed by exposing the SPME fiber to the headspace of each sample for $70 \mathrm{~min}$ at $60^{\circ} \mathrm{C}$, then it was inserted into the GC injection port for desorption $\left(260^{\circ} \mathrm{C} / 5 \mathrm{~min}\right.$ in splitless mode). Before use, the fiber was conditioned in the injection port of the GC $\left(270^{\circ} \mathrm{C} / 1 \mathrm{~h}\right)$, as recommended by the manufacturer. Extraction was carried out in triplicate for each sample.

\section{Gas chromatography-mass spectrometry (GC-MS) analysis}

The GC-MS analysis was carried out according to our previous study (Fadel et al., 2018). The analysis of the volatile compounds of each sample was performed by a gas chromatography (Hewlett-Packard model 5890, USA) coupled to a mass spectrometer (HewlettPackard-MS 5970, USA). The mass spectrometer was operated in the electron impact mode (EI) at $70 \mathrm{eV}$ and scan $\mathrm{m} / \mathrm{z}$ range from 39 to $400 \mathrm{amu}$. The retention indices (Kovats index) of the separated volatile compounds were calculated with reference to the retention time of a series of n-paraffin (C6-C20) as an external standard run in the same conditions. The isolated peaks were identified by matching with data from the library of mass spectra (National Institute of Standard and Technology, NIST) and comparing them with those of authentic compounds and published data (Baek et al., 2001; Song and Xia, 2008; Wu and Cadwallader, 2002). The amount of each individual compound was expressed as total ion chromatograms (TIC).

\section{Statistical analysis}

The data were analyzed using the analysis of variance (ANOVA) by the Statgraphics package (Statistical Graphics Corporation, 1993; Manugistics Inc., USA). The multiple range least significant difference test L.S.D. and Duncan multiple range test were applied to the results $(P<0.05)$.

\section{RESULTS AND DISCUSSION}

\section{TEM analysis of soybean protein isolate nanoparticles}

The morphology of the samples of soybean protein isolate before $\left(\mathrm{SPI}_{\mathrm{b}}\right)$ and after transformation to nanoparticles was investigated under TEM. The untreated $\mathrm{SPI}_{b}$ sample showed spherical shaped particles with average sizes in the range from 155.46 to $222.52 \mathrm{~nm}$ 

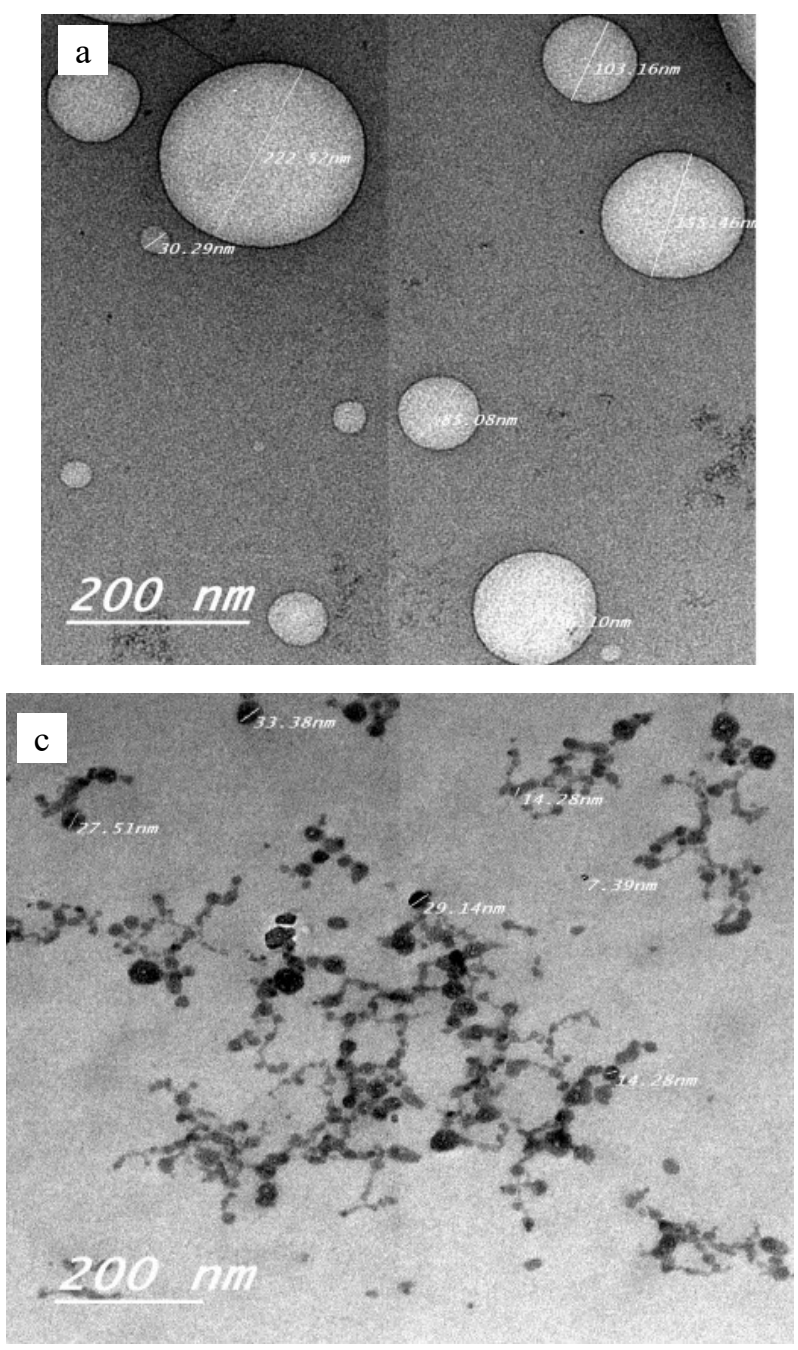
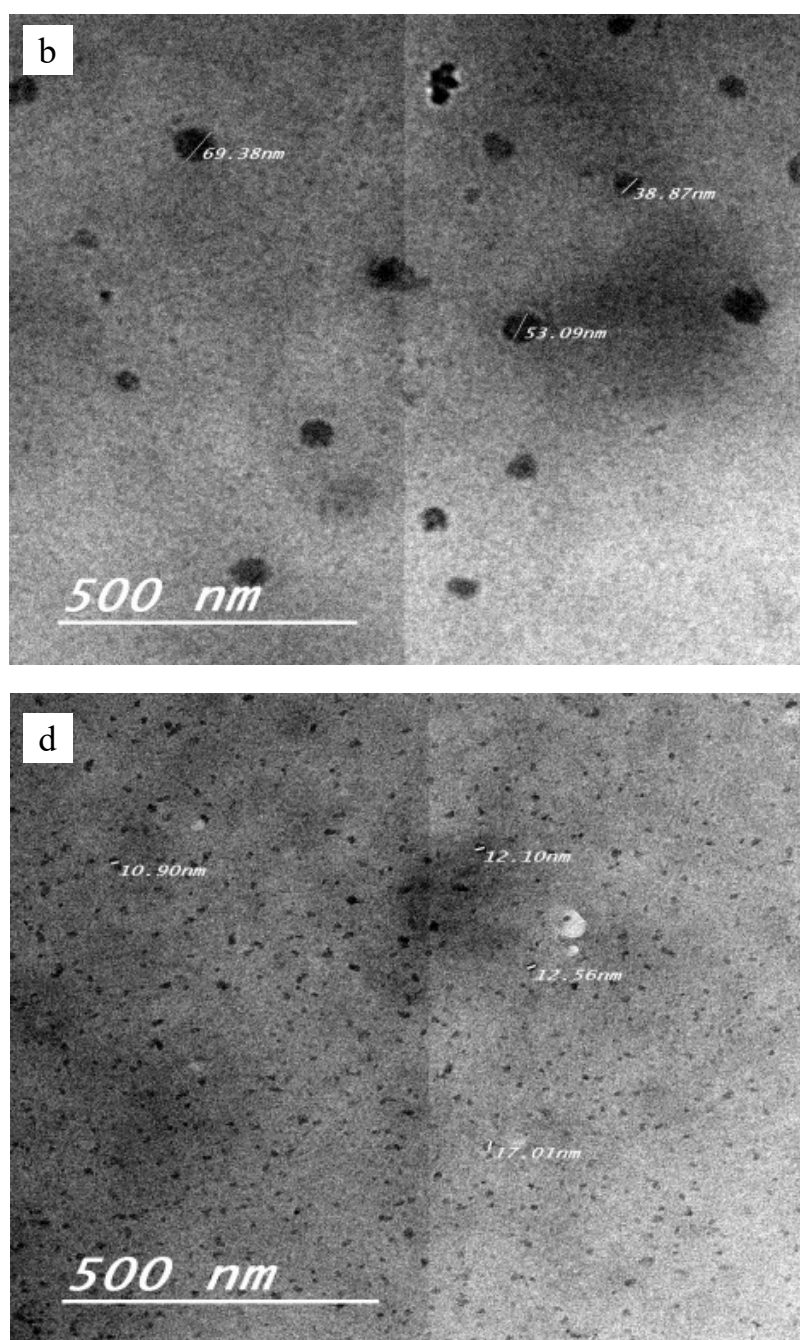

Fig. 1. Transmission electron microscopy (TEM) images of soybean protein isolate before and after transformation into nanopartecles: $\mathrm{a}$ - soybean protein isolate $\mathrm{SPI}_{\mathrm{b}}, \mathrm{b}$ - soybean protein isolate ball milled for $1 \mathrm{~h}\left(\mathrm{SPIN}_{1} \mathrm{~A}\right), \mathrm{c}-$ soybean isolate protein ball milled for $1.5 \mathrm{~h}\left(\mathrm{SPIN}_{1} \mathrm{~B}\right), \mathrm{d}$ - soybean protein isolate nanoparticles prepared on three steps $\mathrm{SPIN}_{3}$

(Fig. 1a). The TEM result of the SPIN ${ }_{1}$ A after ball milling $(1 \mathrm{~h})$ is shown in Figure $1 \mathrm{~b}$. The resulting nanoparticles showed a spherical shape with a diameter ranging from 38.87 to $69.38 \mathrm{~nm}$. Increasing the milling time from 1 to $1.5 \mathrm{~h}$ revealed a remarkable decrease in the SPI nanoparticle $\left(\right.$ SPIN $_{1}$ B) sizes to become 7.39-33.38 nm (Fig. 1c). The high energy generated during the milling process disintegrates the microparticles into nanoparticles (Peltonen and Hirvonen, 2010). A long time is required for ball milling to produce nanosized particles (Hu et al., 2004). Sample SPIN ${ }_{1}$ B showed that the smallest particles sizes were subjected to further treatment (high speed homogenization followed by ultrasonication at different time). The range of the nanoparticles sizes of each sample was measured by TEM (data not shown). The sample showed the smallest range $(10-17 \mathrm{~nm})$ after the three nanotechnology steps $\left(\mathrm{SPIN}_{3}\right)$ was selected (Fig. 1d). This remarkable decrease in the sizes of the nanoparticles confirms the effectiveness of high-speed 
homogenization with ultrasonication in reducing and stabilizing the particle sizes of the nanoparticles produced by ball milling (Van Eerdeubrugh et al., 2008; Williams et al., 2013). High-speed homogenization gave rise to a change in the tertiary structure of proteins such as cross-section bisulphides S-S communication between cysteine molecules (Rogov et al., 2011). Ultrasonic waves induce a wide range of mechanical effects in liquid that are required for controlling the particle sizes (Schroeder, 2013).

\section{Degree of hydrolysis (DH)}

The relationship between the absorbance at $570 \mathrm{~nm}$ and the concentration of free amino acids $(\mathrm{mg} / \mathrm{L}, \mathrm{L}-$ leucine equivalent) in the samples investigated is shown in Figure 2. The free amino acids content in sample

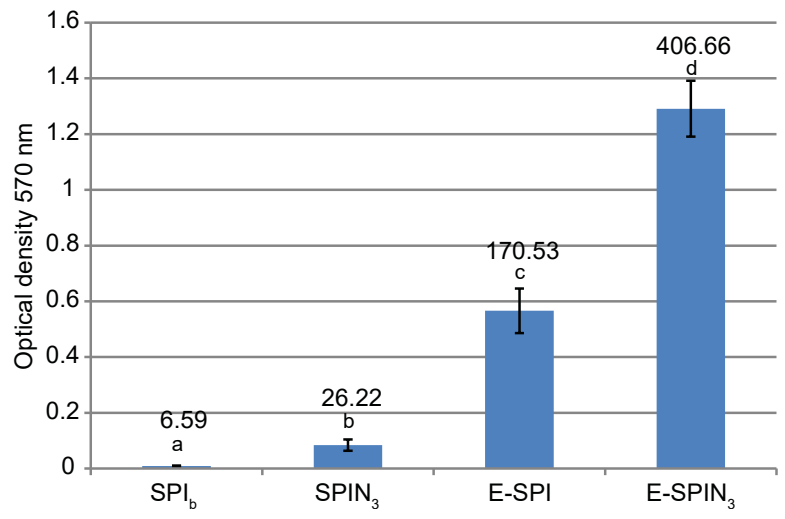

Fig. 2. Optical density at $570 \mathrm{~nm}$ correspond to free amino acids concentration in $\mathrm{SPI}_{\mathrm{b}}$ (before transformation to nanopartcile) and SPI nanoparticles before and after enzymatic hydrolysis (values on the top of each bar $=\mathrm{mg} / \mathrm{mL}, \mathrm{L}-$ leucine equivalent). Optical density followed by different letters means significant difference at $p<0.05$

SPIN $_{3}$ nanoparticles showed more than 4 times greater content in the untreated $\left(\mathrm{SPI}_{\mathrm{b}}\right)$ sample. Applying the nanotechnology processes (three steps) to the SPI before the enzymatic hydrolysis resulted in a marked increase in the degree of hydrolysis (DH) from 22.74 in E-SPI to $54.22 \%$ in E-SPIN ${ }_{3}$, which corresponds with the increase in the content of the amino acids released from 170.53 to $406.66(\mathrm{mg} / \mathrm{L}, \mathrm{L}$ - leucine equivalent) in E-SPI and E-SPIN ${ }_{3}$, respectively.

\section{Composition of free amino acids}

A total of 17 amino acids were detected in the present study (Table 1). It is clear that the total content of the free amino acids in E-SPIN ${ }_{3}$ was more than twice that in the E-SPI. These results confirm those in Figure 2. This finding may be correlated with the fact that the decrease in the particle size to nanoscale gives rise to changes in the mechanical, electrical and optical properties of the particle and subsequently leads to its reactivity (Neethirajan and Jayas, 2011). Glutamic was the major amino acid in the two samples, followed by aspartic, lysine and leucine. The presence of cysteine and methionine only in E-SPIN ${ }_{3}$ may be correlated to the unfolding of protein during preparation

Table 1. Composition of free amino acids in enzymatic hydrolyzed SPI (E-SPI) and enzymatic hydrolyzed SPI nanoparticles $\left(\mathrm{E}_{-} \mathrm{SPIN}_{3}\right)$

\begin{tabular}{|c|c|c|}
\hline \multirow{2}{*}{ Amino acids } & E-SPI & E-SPIN $_{3}$ \\
\hline & \multicolumn{2}{|c|}{$\mathrm{g} / 100 \mathrm{ml}$} \\
\hline Aspartic & $0.20 \pm 0.01$ & $0.45 \pm 0.02$ \\
\hline Threonine & $0.08 \pm 0.00$ & $0.15 \pm 0.00$ \\
\hline Serine & $0.08 \pm 0.00$ & $0.20 \pm 0.01$ \\
\hline Glutamic acid & $0.46 \pm 0.01$ & $0.87 \pm 0.04$ \\
\hline Glycine & $0.08 \pm 0.00$ & $0.16 \pm 0.01$ \\
\hline Alanine & $0.10 \pm 0.00$ & $0.16 \pm 0.01$ \\
\hline Valine & $0.09 \pm 0.00$ & $0.18 \pm 0.01$ \\
\hline Isoleucine & $0.08 \pm 0.00$ & $0.17 \pm 0.01$ \\
\hline Leucine & $0.13 \pm 0.01$ & $0.27 \pm 0.01$ \\
\hline Tyrosine & $0.04 \pm 0.00$ & $0.10 \pm 0.01$ \\
\hline Phenylalanine & $0.10 \pm 0.01$ & $0.19 \pm 0.01$ \\
\hline Hisitidine & $0.05 \pm 0.00$ & $0.11 \pm 0.01$ \\
\hline Lysine & $0.19 \pm 0.02$ & $0.26 \pm 0.03$ \\
\hline Arginine & $0.10 \pm 0.01$ & $0.31 \pm 0.02$ \\
\hline Proline & $0.11 \pm 0.01$ & $0.22 \pm 0.01$ \\
\hline Cystine & $0.01 \pm 0.00$ & $0.04 \pm 0.01$ \\
\hline Methionine & $0.01 \pm 0.00$ & $0.04 \pm 0.01$ \\
\hline Total & $1.91 \pm 0.10$ & $3.88 \pm 0.20$ \\
\hline
\end{tabular}


of nanoparticles that expose interaction groups such as disulfide and thiols and help to release the sulfur-containing compounds during the hydrolysis (Lohcharoenkal et al., 2014).

\section{Volatile compounds}

It is well known that the composition and content of the volatile flavour compounds is highly related to the flavour properties of the sample. Therefore, to interpret the sensory characteristics of the perceived volatiles, the volatile flavour compounds were isolated by HS-SPME and analyzed by GC-MS (Table 2).

A total of 45 volatile compounds were positively identified in the samples investigated. Their total concentration showed higher values in the volatiles generated from enzymatic hydrolyzed SPI protein nanoparticles $\left(\right.$ E-SPIN $\left.{ }_{3}\right)$ than those from the control (E-SPI) sample. Most of the compounds identified were previously reported as Maillard reaction products derived from cysteine-xylose/ribose mixtures, as well as from

Table 2. Composition of volatile compounds identified in meat-like process flavour model mixtures based on enzymatic hydrolysed SPI (E-SPI) and enzymatic hydrolyzed SPI nanoparticles $\left(\mathrm{E}-\mathrm{SPIN}_{3}\right)$

\begin{tabular}{|c|c|c|c|c|c|}
\hline \multirow{2}{*}{ Peak no } & \multirow{2}{*}{$\mathrm{KI}^{\mathrm{a}}$} & \multirow{2}{*}{ Volatile compounds ${ }^{\mathrm{b}}$} & \multicolumn{2}{|c|}{ 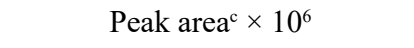 } & \multirow{2}{*}{$\begin{array}{l}\text { Identification } \\
\text { methods }^{\mathrm{d}}\end{array}$} \\
\hline & & & E-SPI & $\mathrm{E}-\mathrm{SPIN}_{3}$ & \\
\hline 1 & 2 & 3 & 4 & 5 & 6 \\
\hline 1 & 603 & 2-methanthiol & - & $5.78 \pm 0.29$ & A \\
\hline 2 & 612 & 2,3-butanedione & $8.54 \pm 0.43$ & $14.31 \pm 0.72$ & A \\
\hline 3 & 656 & 3-methylbutanal & - & $1.36 \pm 0.07$ & A \\
\hline 4 & 685 & 2-pentanone & - & $0.11 \pm 0.01$ & $\mathrm{~B}$ \\
\hline 5 & 718 & 3-pentanone & $0.25 \pm 0.01$ & $0.37 \pm 0.02$ & $\mathrm{~B}$ \\
\hline 6 & 726 & 2,3-pentandione & - & $0.37 \pm 0.02$ & $\mathrm{~B}$ \\
\hline 7 & 735 & 3-hydroxy-2-butanone & 0.01 & $0.15 \pm 0.01$ & $\mathrm{~B}$ \\
\hline 8 & 818 & 3-mercapto-2-butanone & $7.72 \pm 0.39$ & $12.74 \pm 0.64$ & $\mathrm{~B}$ \\
\hline 9 & 871 & 2-methyl-3-furanthiol & $1.55 \pm 0.08$ & $2.46 \pm 0.12$ & A \\
\hline 10 & 914 & 2-furfurylthiol & $0.10 \pm 0.01$ & $0.46 \pm 0.02$ & A \\
\hline 11 & 945 & 2-methyl-3-(methylthio)furan & - & $0.23 \pm 0.01$ & $\mathrm{~B}$ \\
\hline 12 & 955 & dimethyltrisulfide & $1.31 \pm 0.07$ & $1.60 \pm 0.08$ & $\mathrm{~B}$ \\
\hline 13 & 981 & 4,5-dihydro-2-methyl-2(2H)thiophene & $0.11 \pm 0.01$ & - & $\mathrm{B}$ \\
\hline 14 & 995 & 2-methyltetrahydrothiophene-3-one & - & $0.22 \pm 0.01$ & $\mathrm{~B}$ \\
\hline 15 & 1001 & 2-ethyl-3-methylpyrazine & $2.11 \pm 0.11$ & $6.77 \pm 0.34$ & A \\
\hline 16 & 1015 & 4-ethyl-5-methylthiazole & $2.47 \pm 0.12$ & $8.69 \pm 0.44$ & $\mathrm{~B}$ \\
\hline 17 & 1028 & 2-acetythiazole & $1.75 \pm 0.09$ & $3.71 \pm 0.19$ & A \\
\hline 18 & 1032 & trimethylpyrazine & $0.40 \pm 0.02$ & $0.90 \pm 0.05$ & A \\
\hline 19 & 1038 & 2-methyl-3(2H)thiophene & $0.56 \pm 0.03$ & $2.33 \pm 0.12$ & $\mathrm{~B}$ \\
\hline
\end{tabular}


Fadel, H. H. M., Mahmoud, K. F., Saad, R., Lotfy, S. N., Abd El-Aleem, F. S., Ahmed, M. Y. S. (2019). Nanotechnology for enhancing the production of meat-like flavour from enzymatic hydrolyzed soybean protein isolate. Acta Sci. Pol. Technol. Aliment., 18(3), 279-292. http://dx.doi.org/10.17306/J.AFS.2019.0658

Table 2 cont.

\begin{tabular}{|c|c|c|c|c|c|}
\hline 1 & 2 & 3 & 4 & 5 & 6 \\
\hline 20 & 1061 & 2-methyl-3-thiophenethiol & $0.18 \pm 0.01$ & $0.24 \pm 0.01$ & $\mathrm{~B}$ \\
\hline 21 & 1066 & 2-ethyl-3,5-dimethylpyrazine & $1.23 \pm 0.06$ & $2.06 \pm 0.10$ & A \\
\hline 22 & 1106 & 2-ethyl-3,6-dimethylpyrazine & $0.14 \pm 0.01$ & $0.28 \pm 0.01$ & A \\
\hline 23 & 1115 & 2-formyl-5-methylthiophene & - & $0.26 \pm 0.01$ & A \\
\hline 24 & 1130 & 2-formyl-3-methylthiophene & $0.28 \pm 0.01$ & $0.28 \pm 0.01$ & $\mathrm{~B}$ \\
\hline 25 & 1182 & 2-methyl-3-furfurylmethyldisulfide & $0.19 \pm 0.01$ & $0.37 \pm 0.02$ & $\mathrm{~B}$ \\
\hline 26 & 1230 & 2-furfurylmethyldisulfide & $0.11 \pm 0.01$ & $0.22 \pm 0.01$ & $\mathrm{~B}$ \\
\hline 27 & 1255 & 3-methyl-1,2,4-trithiane & $0.14 \pm 0.02$ & $0.23 \pm 0.01$ & B \\
\hline 28 & 1260 & 2,5-thiophenedicarboxyldehyde & $0.94 \pm 0.05$ & $1.90 \pm 0.10$ & $\mathrm{~B}$ \\
\hline 29 & 1268 & 2-acetyl-2,5-dimethylthiophene & $0.26 \pm 0.01$ & $0.50 \pm 0.03$ & $\mathrm{~B}$ \\
\hline 30 & 1307 & ethyl benzothiophene & - & $0.43 \pm 0.02$ & $\mathrm{~B}$ \\
\hline 31 & 1317 & 5-methyl-2 $(5 \mathrm{H})$ thiophenone & $0.14 \pm 0.01$ & - & $\mathrm{B}$ \\
\hline 32 & 1325 & 1-(2-methyl-3-furylthio)ethanthiol & $0.10 \pm 0.01$ & $0.14 \pm 0.01$ & $\mathrm{~B}$ \\
\hline 33 & 1388 & 2-methyl-3-furylmethyltrisulfide & $0.09 \pm 0.01$ & - & $\mathrm{B}$ \\
\hline 34 & 1518 & 3 [(2-methyl-3-furyl)dithio]-2-butanone & - & $1.48 \pm 0.07$ & $\mathrm{~B}$ \\
\hline 35 & 1547 & bis(2-methyl-3-furyl)disulfide & - & $5.33 \pm 0.27$ & $\mathrm{~B}$ \\
\hline 36 & 1551 & 1-(2-furylmethyldithio)-2-propanone & $6.20 \pm 0.31$ & $1.15 \pm 0.06$ & B \\
\hline 37 & 1561 & 3-[(2-methyl-3-furyl)dithio]-2-pentanone & $0.15 \pm 0.021$ & $0.09 \pm 0.06$ & B \\
\hline 38 & 1594 & 2-[(2-furylmethyl)dithio]-2-butanone & $0.08 \pm 0.00$ & - & $\mathrm{B}$ \\
\hline 39 & 1676 & 3-[(2-furylmethyl)dithio]-2-pentanone & $0.05 \pm 0.00$ & $0.21 \pm 0.01$ & B \\
\hline 40 & 1701 & bis(2-furylmethyl)disulfide & $0.10 \pm 0.01$ & $0.08 \pm 0.00$ & $\mathrm{~B}$ \\
\hline 41 & 1720 & $\begin{array}{l}\text { 2-methyl-3-[(2-methyl-3-thienyl)] } \\
\text { dithiofuran }\end{array}$ & $0.07 \pm 0.00$ & $0.14 \pm 0.01$ & $\mathrm{~B}$ \\
\hline 42 & 1769 & (2-methyl-3-thienyl)disulfide & $0.38 \pm 0.02$ & $0.62 \pm 0.03$ & B \\
\hline 43 & 1877 & bis(2- or 3-thienyl)disulfide & $0.28 \pm 0.01$ & $0.46 \pm 0.02$ & $\mathrm{~B}$ \\
\hline 44 & 1937 & bis(2-furyl methyl)trisulfide & $3.02 \pm 0.15$ & $2.07 \pm 0.10$ & $\mathrm{~B}$ \\
\hline \multirow[t]{2}{*}{45} & 1947 & 2-thiophene methanol & - & $0.18 \pm 0.01$ & A \\
\hline & Total & & $41.01 \pm 2.07$ & $81.28 \pm 4.09$ & \\
\hline
\end{tabular}

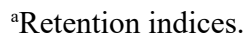

${ }^{\mathrm{b} C}$ Compounds listed according to their elution on DB5 column.

${ }^{\mathrm{c}}$ Results were the means of three replicates of the peak total ion current TIC (peak area $\times 10^{6}$ ).

${ }^{\mathrm{d}}$ Volatile compounds identification was performed as follows: A - mass spectrum and retention index were consistent with those of an authentic standard, B - mass spectrum was identical with that of NIST mass spectrum database, and retention index was consistent with that of the literature. 
a model mixture based on E-HVP (Hou et al., 2017; Wu and Cadwallader, 2002).

As shown in Table 2, the sulfur-containing compounds were dominated by thiol-containing compounds. According to the literature, cysteine and thiamine degradation release hydrogen sulphide, which can act on the intermediates from pentose degradation such as the 1-deoxypentose, 4-hydroxy-2-methyl$-3(2 \mathrm{H})$ furanones, 5-hydroxy-2,3-pentadione and result in the formation of sulphur containing compounds (Hincelin et al., 1992).

3-Mercapto-2-butanone (8) was the major identified compound in the two samples (E-SPI and E$\mathrm{SPIN}_{3}$ ). It possesses a meaty, cooked rice aroma (Song and Xia, 2008) and was reported as a character-impact compound of process flavouring from several Maillard model systems containing cystein and different sugars (Mottram and Nobrega, 1998) and enzymatic hydrolyzed vegetable protein/cystein and ribose (Wu and Cadwallader, 2002). Compound 8 was the major thiol compound identified in the volatiles of beef soup (Abd El-Aleem et al., 2017). It is probably formed from the reaction of the corresponding alkandione, 2,3-butanedione (2) (breakdown product of sugar) with hydrogen sulfide at a low $\mathrm{pH}$ (Madruga and Mottram, 1998).

2-Methyl-3-furanthiol (2MF, 9) was identified in the two samples under investigation (E-SPI and E$-\mathrm{SPIN}_{3}$ ) with considerable concentration of 1.55 and $2.46 \times 10^{6} \mathrm{TIC}$, respectively. It is the most important odour impact compound of beef aromas (Song et al., 2010). Adding sulfur-containing amino acids to HVPs gave rise to the generation of a high yield of 2MF (Baek et al., 2001; Lotfy et al., 2015; Wu and Cadwallder, 2002). Previously, Hincelin et al. (1992) had proposed that thiamine degradation was the primary formation pathway of $2 \mathrm{MF}$, whereas Cerny (2007) reported that both precursors have a similar part in the formation of $2 \mathrm{MF}$.

The other thiol containing compounds were 2-methanthiol (1), 2-furfurylthiol (10), 2-methyl-3-thiophenethiol (20) and 1-(2-methyl-3-furylthio) ethanthiol (32). Compounds 9 and $\mathbf{1 0}$ were shown to be important odorants in commercial meat flavourings, as well as cooked beef and chicken broth (Gasser and Grosch, 1990). Compound 10 was probably formed by the reaction of hydrogen sulfide (Strecker degradation of cysteine) with furfural (a sugar degradation product)
(Mottram and Leseigneur, 1990). Compound 20 was identified among other thiols in the volatiles of the ribose and cysteine model system heated at $140^{\circ} \mathrm{C}$ under supercritical carbon dioxide $\left(\mathrm{Sc}^{-} \mathrm{Co}_{2}\right)(\mathrm{Xu}$ et al., 2010). It was also detected in the volatiles of different model systems containing cysteine and xylose (Cerny, 2007; Hou et al., 2017). Furans and thiophenethiols have been reported as important volatiles in cooked meat. Compound $\mathbf{3 2}$ was detected in the volatiles generated in the meat model reaction mixture, xylose/cysteine/ glycine (Hou et al., 2017) at $\mathrm{pH}$ 5. It also was identified as one of the potent odorants of meat.

Compounds: 2-methyl-3-(methylthio)furan (11), 2-methyl-3-furfurylmethyl disulfide (25), 2-furfurylmethyldisulfide (26), 3-[(2-methyl-3-furyl)dithio]-2-butanone (34), bis (2-methyl-3-furyl)disulfide (35), 1-(2-furylmethyldithio)-2-propanone (36), 3-[(2-methyl-3-furyl)dithio]-2-pentanone (37), 2-[2-furylmethyldithio]-2-butanone (38), 3-[(2-furyl methyl) dithio]-2-pentanone (39), bis(2-furylmethyl)disulfide (40), 2-methyl-3-[(2-methyl-3-thienyl)]dithiofuran (41), (2-methyl-3-thienyl)disulfide (42) and bis(2- or 3-thienyl)disulfide (43) are the identified disulfide compounds (Table 2). Compounds 34, 35, 36, 37, 38, 39, 40 and $\mathbf{4 1}$ are dimers of their corresponding thiols, their extremely low thresholds impart a high potency in the odour profile of flavourings (Xu et al., 2010). As shown in Table 2, compound 35 was found in a high concentration in the E-SPIN ${ }_{3}$ sample, whereas it was absent in E-SPI. It is well documented that compound 9 easily oxidizes to its dimer compound $\mathbf{3 5}$, and these two compounds had previously been identified as the odour impact compounds of beef aroma (Song et al., 2010) and other model systems for preparing meat-like flavours, and gave various characteristic aromas described as "sweet meat", "beef broth" and "braised beef" (Moon et al., 2006). However, at high concentrations, the odour quality changed from "meaty" to "pungent" and/ or "sulphurous", due to their low odour threshold value, e.g. the odour perception threshold of $2 \mathrm{MF}$ is $0.005-0.01 \mathrm{lg} / \mathrm{kg}$.

Compounds 9, 11, 34, 35, 36 and 38 were detected as active compounds in the volatiles of beef-like process flavour produced by extrusion of enzyme hydrolyzed vegetable protein with flavour precursors; cysteine, thiamine, methionine and fructose (Baek et al., 2001). Compounds 11 and 25 were proposed to be 


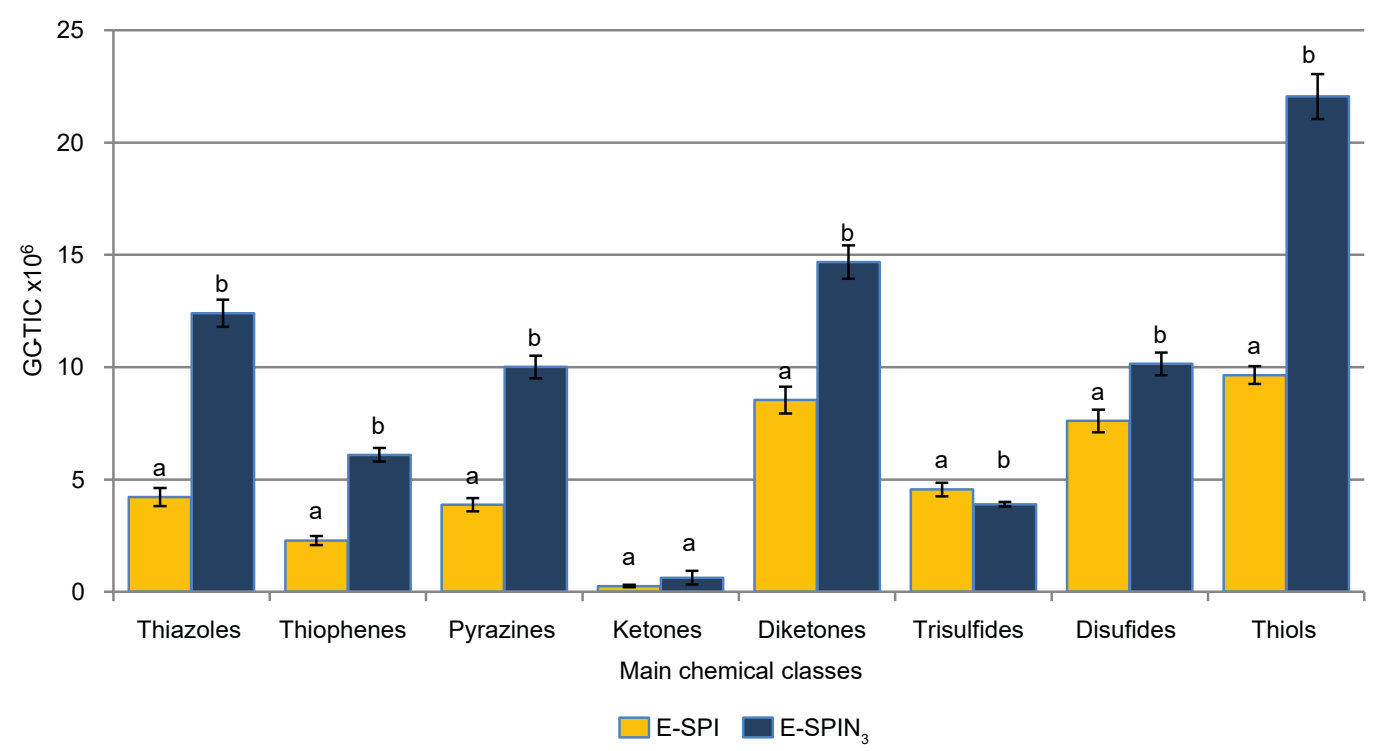

Fig. 3. The main chemical classes of volatile compounds generated from model mixtures based on enzymatic hydrolyzed SPI nanoparticles $\left(\mathrm{E}-\mathrm{SPIN}_{3}\right)$ and hydrolyzed SPI (control, E-SPI). GC-TIC value of each chemical class followed by different letters means significant difference at $p<0.05$

formed via a Maillard reaction of ribose and cysteine, involving the reaction with methanethiol, or $2 \mathrm{MF}$ with methanthiol (Mottram and Whitfield, 1995). Compound 36 comprised a higher concentration in the control sample (E-SPI) compared with sample E-SPIN (Table 2). Compounds 37, 38 and $\mathbf{3 9}$ were described to have sulfury, onion, roasted notes (Madruga and Mottram, 1995).

Dimethyl trisulfide (12), 3-methyl-1,2,4-trithiane (27) and bis(2-furyl methyl)trisulfide (44) are the polysulfide compounds identified in the present study (Table 2). Compound 12 was detected in the volatiles of the extruded enzymatic hydrolyzed protein and sulfur containing amino acids (Baek et al., 2001; Song and $\mathrm{Xia}, 2008)$, it possesses meaty, onion, and garlic notes. Compound $\mathbf{4 4}$ showed a higher concentration in sample E-SPI, and was described to have, roasted sulfury notes (Madruga and Mottram, 1995).

Compounds: 4,5-dihydro-2-methyl-2(2H)thiophene (13), 2-methyl tetrahydrothiophene-3-one (14), 2-methyl-3(2H)thiophene (19), 2-formyl-5-methylthiophene (23), 2-formyl-3-methylthiophene (24), 2,5-thiophenedicarboxyaldehyde (28), 2-acetyl-2,5-dimethylthiophene (29), ethyl benzothiophene (30), 5-methyl-2-(5H) thiophenone (31) and 2-thiophene methanol (45) were the ten thiophenes detected in the present study with a total yield 2.29, $6.10 \times 10^{6} \mathrm{TIC}$ in E-SPI and E-SPIN ${ }_{3}$, respectively (Fig. 3), and among them compounds 14, 23 and $\mathbf{3 0}$ were absent in the E-SPI sample. Thiophene and its substituted derivatives were an important category of compounds found in ribose-cysteine reaction products (Xu et al., 2010) and xylose-cysteine reaction products (Xu et al., 2011).

Compounds: 4-ethyl-5-methylthiazole (16) and 2-acetylthiazole (17) were identified in both samples. Their total yield in sample E-SPIN ${ }_{3}$ was four times that in the E-SPI sample. Compound 16 possess meaty notes, whereas compound $\mathbf{1 7}$ has roasty, popcorn notes (Wu and Cadwallader, 2002).

Pyrazines with a low odour threshold associated with the roasty flavour are formed via a Maillard reaction. Four pyrazines were identified in the present study (Table 2) namely 2-ethyl-3-methylpyrazine (15), trimethylpyrazine (18), 2-ethyl-3,5dimethylpyrazine (21) and 2-ethyl-3,6-dimethylpyrazine (22). Compound (15), the major identified pyrazine in the two samples, was detected in the volatiles of the meatlike model system (Ba et al., 2013). Compound (18) possesses burnt nutty note (Hou et al., 2017). Compound (21) was determined among the potent odorants 


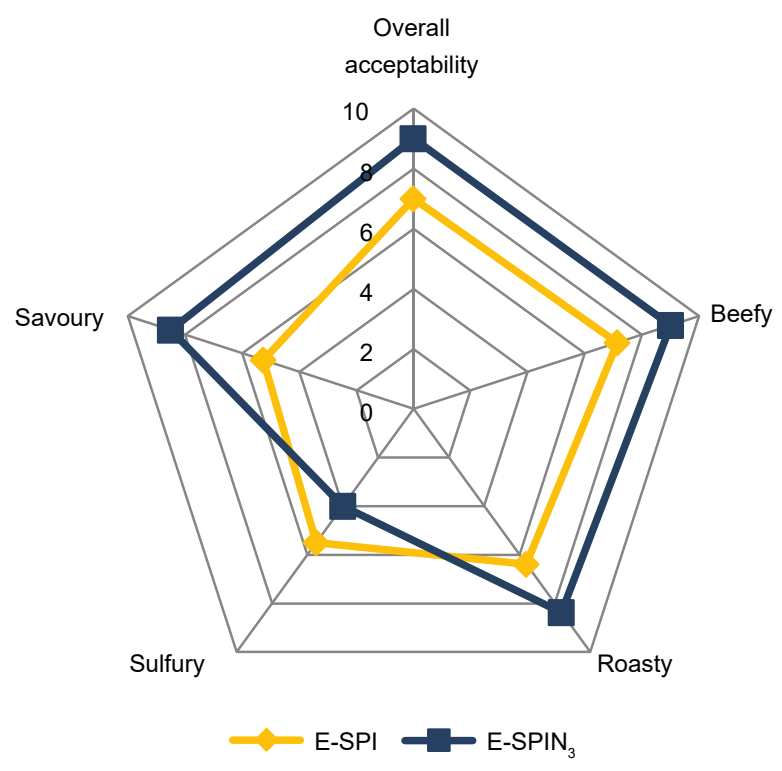

Fig. 4. Aroma profile of meat model mixtures based on enzymatic hydrolyzed SPI nano-particles $\left(\mathrm{E}_{-} \mathrm{SPIN}_{3}\right)$ and enzymatic hydrolyzed untreated SPI (E-SPI)

of beef flavouring prepared from a thermal reaction model system of enzymatically hydrolyzed beef/amino acids and sugar (Song and Xia, 2008). Compound (22), on the other hand, was found in the headspace volatiles of meat cooked with or without the addition of cysteine or thiamine (Madruga, 1997), also in the volatiles of beef-like process flavours (Song et al., 2010). As shown in Table 2 and Figure 3, the total yield of pyrazines in the E-SPIN ${ }_{3}$ sample was approximately twice that in the E-SPI sample. This finding may be correlated to the increase in the amount of the basic amino acids such as lysine and arginine in the ESPIN $_{3}$ nanoparticles (Table 1) compared with the control sample. Pyrazines in addition to sulfur-containing compounds are thought to impart a beef-like flavour to the beef-like flavourings prepared from HVP and sulfur-containing amino acids (Baek et al., 2001).

\section{Odour sensory analysis}

According to the results of GC-MS analysis, the beefy attribute-related compounds showed a significant increase in the aroma of E-SPIN ${ }_{3}$ compared with that of the E-SPI sample. The compounds detected by GC-MS analysis should be positively correlated with attributes in descriptive sensory analysis (Song et al.,
2010). Therefore, descriptive sensory analysis was conducted to explore the effect of subjecting SPI to nanotechnology before enzymatic hydrolysis, on the acceptability of the prepared beef-like flavour.

The sensory attributes; beefy, roasty, sulphurous, savoury and overall acceptability were selected and scored by panelists. Three replicates were applied to assess the results (Fig. 4). The beefy, roasty, savoury and overall acceptability showed higher scores in the $\mathrm{E}_{-\mathrm{SPIN}_{3}}$ sample compared with sample E-SPI, whereas the opposite trend was found for sulfurous notes. As shown in Table 2, the total yield of the compounds 9, 25, 32, 33, 34, 35 and 37 in sample E-SPIN ${ }_{3}$ was higher than that in the E-SPI sample. As was reported in a previous study (Song and Xia, 2008), the compounds containing 2-methyl-3-furyl moiety possess meaty aromas. In addition, compounds 11 and 16, which are considered as potent odorants of beef aroma (Hou et al., 2017), were detected in higher concentrations in E-SPIN ${ }_{3}$ than in the E-SPI sample. As shown in Figure 4, the E-SPIN ${ }_{3}$ sample showed a higher score of roasty note compared with sample E-SPI. This observation may be attributed to the higher total yield of the compounds containing 2-furfuryl groups (compounds 10, 26, 36, 38, 39 and 40), in E-SPIN ${ }_{3}$, which had been described to give roasted, nutty, meaty and sulfurous notes (Song and Xia, 2008). Also, the higher yields of thiazoles and pyrazines (Fig. 3) in E-SPIN compared with E-SPI are responsible for the roasty note. Compound 2-ethyl-3,5-dimethylpyrazine (21) was detected only in beef-like process flavour with added precursors (Baek et al., 2001). The savoury note showed a significant higher score $(P<0.05)$ in sample E-SPIN ${ }_{3}$ compared with sample E-SPI. This finding is consistent with the higher yield of the disulfide compounds (Fig. 4). These compounds possess savoury aromatic notes and generally come from the dehydrogenation among furanthiols, thiophethiols and $\alpha$-mercaptoketones (Chen and Ho, 2002).

\section{CONCLUSION}

Using protein nanoparticles as the main precursors of the process flavours is considered a new chance innovation in nanoscience. Preparations of soybean isolate nanoparticles in three steps, ball milling coupled with high-speed homogenization and ultra-sonication, 
gave rise to a significant reduction in the sizes of the resulting nanoparticles compared with the untreated sample. Applying these nano technological techniques led to an unfolding of the protein and consequently assisted its enzymatic hydrolysis. The increase in the total yield of the headspace volatiles of meat-like flavour generated from soybean isolate nanoparticles as a main precursor is correlated to the high content of the free amino acids released compared with the untreated sample. The higher content of thiol-containing compounds, the most potent odorants of meat-like aro$\mathrm{ma}$, in the volatiles generated from the enzymatic hydrolyzed soybean protein isolate nanoparticles compared with the control sample may be correlated to the presence of sulfur-containing amino acids only in the former sample. An agreement was found between the results of the GC-MS analysis and those of the odour sensory.

\section{REFERENCES}

Aaslyng, M. D., Elmore, J. S., Mottram, D. S. (1998). Comparison of the aroma characteristics of acid-hydrolyzed and enzyme hydrolyzed vegetable proteins produced from soy. J. Agric. Food Chem., 46, 5225-5231. https:// doi.org/10.1021/jf9806816

Abd El-Aleem, F. A., Taher, S. M., Lotfy, S. N., El-Massrey, K. F., Fadel, H. H. M. (2017). Influence of extracted 5-nucleotides on aroma compounds and flavour acceptability of real beef soup. Int. J. Food Prop., 20(S1), S1182-S1194. https://doi.org/10.1080/10942912.2017. 1286506

Ba, V. H., Touseef, A., Inho, H. (2013). Significant influence of particular unsaturated fatty acids and $\mathrm{pH}$ on the volatile compounds in meat-like model systems. Meat Sci., 94, 480-488. https://doi.org/10.1016/j.meatsci.2013.04.029

Baek, H. H., Kim, C. J., Ahn, B. H., Nam, H. S., Cadwallader, K. R. (2001). Aroma extract dilution analysis of a beef-like process flavour from extruded enzyme-hydrolyzed soybean protein. J. Agric. Food Chem., 49, 790-793.

Cerny, C. (2007). Origin of carbons in sulphur-containing aroma compounds from the Maillard reaction of xylose, cysteine and thiamine. LWT - Food Sci. Technol., 40, 1309-1315. https://doi.org/10.1016/j.lwt.2006.09.008

Chen, Y., Ho, C.-T. (2002). Effect of carnosine on volatile generation from Maillard reaction of ribose and cysteine. J. Agric. Food Chem., 50, 2372- 2376. https:// doi.org/10.1021/jfo112441

DeFrates, K., Markiewicz, T., Gallo, P., Rack, A., Weyhiller, A., Jarmusik, B, Hu, X. (2018). Protein polymerbased nanoparticles: Fabrication and medical applications. Int. J. Mol. Sci., 19, 1717. http://doi.org/10.3390/ ijms 19061717

Fadel, H. H. M., Lotfy, S. N., Asker, M. M. S., Mahmoud, M. G., Al-Okbi, S. Y. (2018). Nutty- like flavor production by Corynbacterium glutamicum 1220T from enzymatic soybean hydrolysate. Effect of encapsulation and storage on the nutty flavoring quality. J. Adv. Res., 10, 31-38. https://doi.org/10.1016/j.jare.2018.01.003

Folkertsma, B., Fox, P. F. (1992). Use of the Cd-ninhydrin reagent to assess proteolysis in cheese during ripening. J. Dairy Res., 59, 217-224. https://doi.org/10.1017/ S0022029900030466

Gasser, U., Grosch, W. (1990). Primary odorants of chicken broth. Z. Lebensm. Unters. Forsch., 190, 3-8.

Hincelin, O., Ames, J. M., Apriyantono, A., Elmore, J. S. (1992). The effect of xylose on the generation of volatiles from heated thiamin. Food Chem., 44, 381-389.

Hou, L., Xie, J., Zhao, J., Zhao, M., Fan, M., Xiao, Q., ..., Chen, F. (2017). Role of different initial Maillard intermediates and pathways in meat flavor formation for cysteine-xylose-glycine model reaction systems. Food Chem., 232, 135-144. https://doi.org/10.1016/j.foodchem.2017.03.133

Hu, J. H., Johnston, K. P., Williams, R. O. (2004). Nanoparticle engineering processes for enhancing the dissolution rates of poorly water soluble drugs. Drug Dev. Ind. Pharm., 30, 233-245. https://doi.org/10.1081/DDC120030422

IOFI (2010). International Organization of Flavour Industry. Food Safety and Uses of Food Flavourings.

Lilliehorn, T., Simu, U., Nilsson, M., Almqvist, M., Stepinski, T., Laurell, T., ..., Johansson, S. (2005). Trapping of microparticles in the near field of an ultrasonic transducer. Ultrasonics, 43, 293-303. https://doi.org/10.1016/j. ultras.2004.11.001

Liu, S. C., Yang, D. J., Jin, S. Y., Hsu, C. H. , Chen, S. L. (2008). Kinetics of color development, $\mathrm{pH}$ decreasing and antioxidative reduction of Maillard reaction in galactose/glycine model systems. Food Chem., 108, 533541. https://doi.org/10.1016/j.foodchem.2007.11.006

Loh, Z. H., Samanta, A. K., Heng, P. W. S. (2015). Overview of milling techniques for improving the solubility of poorly water-soluble drugs. Asian J. Pharm. Sci., 10, 255-274. https://doi.org/10.1016/j.ajps.2014.12.006 
Lohcharoenkal, W., Wang, L., Chen, Y. C., Rojanasakul, Y. (2014). Protein nanoparticles as drug delivery carriers for cancer therapy. BioMed Res. Int., 2014, 1-12. http:// dx.doi.org/10.1155/2014/180549

Lotfy, S. N., Fadel, H. H. M., El-Ghorab, A. H., Shaheen, M. S. (2015). Stability of encapsulated beef-like flavourings prepared from enzymatically hydrolysed mushroom proteins with other precursors under conventional and microwave heating. Food Chem., 187, 7-13. https:// dx.doi.org/10.1016/j.foodchem.2015.04.027

Loureiro, A., Nogueria, E., Azoia, N. G., Sarria, M. P., Abreu, S., Shimanovich, U., ..., Cavaco-Paulo, A. (2015). Size controlled protein nanoemulsion for active targeting of folate receptor positive cells. Colloids Surf. B: Biointerfaces, 135, 90-98. https://doi.org/10.1016/j. colsurfb.2015.06.073

Madruga, M. S. (1997). Studies on some precursor involved in meat flavor formation. Ciência Tecnol. Alim., 17, 148-153. http://dx.doi.org/10.1590/S010120611997000200016

Madruga, M. S., Mottram, D. S. (1995). The effect of $\mathrm{pH}$ on the formation of Maillard derived aroma volatile using a cooked meat system. J. Sci. Food Agric., 86, 305-310. https://doi.org/10.1002/jsfa.2740680308

Madruga, M. S., Mottram, D. S. (1998). The effect of $\mathrm{pH}$ on the formation of volatile compounds produced by heating a model system containing 5-IMP and cysteine. J. Braz. Chem. Soc., 9, 261-271. https://doi.org/10.1590/ s0103-50531998000300010

Merisko-Liversidge, E., Liversidge, G. G., Cooper, E. R. (2003). Nanosizing: a formation approach for poorlywater soluble compounds. Eur. J. Pharm. Sci., 18, 113120.

Moon, S. Y., Cliff, M. A., Li-Chan, E. C. Y. (2006). Odouractive components of simulated beef flavour analyzed by solid phase microextraction and gas chromatographymass spectrometry and -olfactometry. Food Res Int., 39, 294-308. https://doi.org/10.1016/j.foodres.2005.08.002

Mottram, D. S., Nobrega, I. C. C. (1998). Formation of volatile sulphur compounds in reaction mixtures containing cysteine and three different ribose compounds. In E. T. Contis, A. M. Spanier, F. Shahidi (Eds.), Food flavors: Formation, analysis and packaging influences. Proceedings of the 9th international flavour conference (pp. 483-492). Amsterdam: Elsevier. https://doi. org/10.1016/s0167-4501(98)80070-8

Mottram, D. S., Whitfield, F. B. (1995). Maillard-lipid interaction in non-aqueous systems with phosphatidyl choline. J. Agric. Food Chem., 43, 1302-1306. https://doi. org/10.1021/jf00053a033
Mottram, D. S., Leseigneur, A. (1990). The effect of $\mathrm{pH}$ on the formation of aroma volatiles in meat-like Maillard systems. In Y. Bessière, A. F. Thomas (Eds.), Flavour science and technology (pp. 121-124). New York: John Wiley.

Neethirajan, S., Jayas, S. D. (2011). Nanotechnology for food and bioprocessing industries. Food Bioproc. Tech., 4, 39-47. https://doi.org/10.1007/s11947-010-0328-2

Peltonen, L., Hirvonen, L. (2010). Pharmaceutical nanocrystals by nanomilling: critical process parameters, particle fracturing and stabilization methods. J. Pharm. Pharmacol., 26, 1569-1579. https://doi.org/10.1111/ j.2042-7158.2010.01022.x

Rahimnejad, M., Mokhtarian, N., Ghasemi, M.(2009). Production of protein nanoparticles for food and drug delivery system. Afr. J. Biotechnol., 8, 4738-4743.

Riche, M., Williams, T. N. (2010). Apparent digestible protein, energy and amino acids availability of three plant proteins in Florida pompano, Trachinotus carolinus L. in seawater and low-salinity water. Aquacult. Nutr., 16, 223-230. https://doi.org/10.1111/j.1365-2095.2009.00 654.x

Roa, D. F., Santagapita, P. R., Buera, M. P., Tolaba, M. P. (2014). Ball milling of amaranth starch-enriched fraction. Changes on particle size starch crystallinity, and functionality as a function of milling energy. Food Bioproc. Tech., 7, 2723-2731. https://doi.org/10.1007/ s11947-014-1283-0

Rogov, I. A., Danilchuk, T. N., Shushkevich, J. A., Semenov, G. V., Ovchinnikova, O. E. (2011). Nanostructure and new properties of hydrolyzed food globular properties. J. Phys. Conf. Ser. 291: 012007. https://doi. org/10.1088/1742-6596/291/1/012007

Saloko, S., Darmadji, P., Setiaji, B., Pranoto, Y., Anal, A. K. (2013). Encapsulation of coconut shell liquid smoke in chitosan-maltodextrin based nanoparticles. Int. Food Res. J., 20, 1269-1276.

Schroeder, A. (2013). Using ultrasound to formulate nanotherapeutics. Chim. Oggi-Chem. Today, 31, 54-56.

Song, H., Xia, L. (2008). Aroma extract dilution analysis of a beef flavour prepared from flavour precursors and enzymatically hydrolyzed beef. Flavour Fragr. J., 23, 185-193. https://doi.org/10.1002/ffj.1873

Song, S., Zhang, X., Hayat, K., Huang, M., Liu, P., Karangwa, E., ..., Niu, Y. (2010). Contribution of beef base to aroma characteristics of beef-like process flavor assessed by descriptive sensory analysis and gas chromatography-mass spectrometry and partial least squares regression. J. Chromatogr. A, 1217, 7788-7799. https:// doi.org/10.1016/j.chroma.2010.10.046 
Van Eerdenbrugh, B., Van den Mooter, G., Augustijns, P. (2008). Top down production of drug nanoparticles: nanosuspension stabilization, miniaturization and transformation into solid products. Int. J. Pharm., 364, 64-75. https://doi.org/10.1016/j.ijpharm.2008.07.023

Verma, D., Gultai, N., Kaul, S., Mukherjee, S., Nagaich, U. (2018). Protein based nanostructures of drug delivery. J. Pharm., 16, 2018: 9285854. http://dx.doi. org/10.1155/2018/9285854

Williams, H. D., Trevaskis, N. L., Charman, S. A. (2013). Strategies to address low protein solubility in discovery and development. Pharm. Rev., 65, 315-499. https://doi. org/10.1124/pr.112.005660

Wu, G. Y., Cadwallader, R. K. (2002). Characterization of the aroma of a meat-like process flavouring from soybean-based enzyme hydrolyzed vegetable protein.
J. Agric. Food Chem., 50, 2900-2907. https://doi. org/10.1021/jf0114076

Xu, H., He, W., Liu, X., Gao, Y. (2010). Effect of pressure on the Maillard reaction between ribose and cysteine in supercritical carbon dioxide. Czech J. Food Sci., 28, 192-201.

Xu, Y., Chen, Q., Lei, S., Wu, P., Fan, G., Xu, X., Pan, S. (2011). Effect of lard on the formation of volatiles from Maillard reaction of cystein with xylose. J. Sci. Food Agric., 91, 2241-2246. https://doi.org/10.1002/jsfa.4445

Yu, L. W., Yan, D. Y., Sun, G., Gu, L. X. (2008). Preparation and characterization of $\mathrm{pH}$-sensitive hydrogel fibers based on hydrolyzed-polyacrylonitrile soy proteins. J. Appl. Polym. Sci., 108, 1100-1108. https://doi. org/10.1002/app.27689 